\title{
The Bernhard Nocht Institute: 100 Years of Tropical Medicine in Hamburg
}

\author{
Bernhard Fleischer
}

Bernhard-Nocht Institut für Tropenmedizin, Bernhard-Nocht-Str. 74, D-20359 Hamburg, Germany

The Bernhard Nocht Institute (BNI) is a four months younger and much smaller sibling of the Instituto Oswaldo Cruz. It was founded on 1 October 1900 as an Institut für Schiffs- und Tropenkrankheiten (Institute for Maritime and Tropical Diseases) and was later named after its founder and first director Bernhard Nocht. Today it is the Germany's largest institution for research in tropical medicine. It is a government institution affiliated to the Federal Ministry of Health of Germany and the Department of Health of the State of Hamburg. As the center for research in tropical medicine in Germany the BNI is dedicated to research, training and patient care in the area of human infectious diseases, which are of particular relevance in the tropics. It is the primary mission of the BNI to develop means to the control of these diseases. Secondary missions are to provide expertise for regional and national authorities and to directly and indirectly improve the health care for national and regional citizens in regard to diseases of the tropics.

Key words: Bernhard Nocht Institute - tropical medicine - research

\section{PAST}

The roots of the Bernhard Nocht Institute (BNI) lie in the great cholera outbreak in Hamburg in 1892 during its fifth pandemic. Bernhard Nocht (1957-1945), a young Navy Doctor who had been trained at Robert Koch's Institut in Berlin, came to Hamburg to help Koch to bring the epidemic under control. Because of his ability, it was subsequently offered him the position of a Harbour Doctor and he was appointed in 1893.

In this office Nocht saw the great and increasing number of sailors and travelers with tropical diseases entering Hamburg by ship. In the year 1900 , for example, 500 ships with 15,000 persons arrived from overseas in the port of Hamburg. Tropical and other infections such as typhus, dysenteries or tuberculosis were commonly seen. For example, $11 \%$ of the travelers that arrived on sailing ships had malaria and $6 \%$ of travelers from steam ships.

From a previous visit to the tropics, Nocht had experience with tropical diseases and tried to persuade the authorities of the need to establish an Institute for research, training and therapy of tropical infections.

Fax: +49-40-42818.400

E-mail: fleischer@bni-hamburg.de

Received 7 August 2000

Accepted 4 September 2000
Although Robert Koch tried to bring such an Institute to Berlin at Nocht's instigation, an Institut für Schiffs-und Tropenkrankheiten (Institute for Maritime and Tropical Diseases) was founded in Hamburg on 1 October 1900. Nocht was the first director, acting from 1900 to 1930 . Within a short time he was able to gather a group of ambitious and able scientists (Fig. 1). Fritz Schaudinn, who discovered Treponema pallidum, was the first head of the Department of Protozoology. After his sudden death in 1906, Stanislaus von Prowazek was his successor. Gustav Giemsa, the inventor of the famous Giemsa stain, started to work in 1900 as head of the Department of Chemistry. Friedrich Fülleborn, later Nocht's successor as director, was the first head of the Department of Helminthology.

In 1914, the Institute had, besides the director, six scientists on its own payroll and four scientists were financed by the army or the colonial office. In this year the Institute moved into a new building that still today accomodates it (Fig. 2). The costs of the building were 1,500,000 marks and of the interior 800,000 marks. The annual budget for research of the Institute in 1914 was 246,302 marks.

In the first decades of the BNI a number of major discoveries was made. Milestones were the discovery of Rickettsia prowazecki, the agent of epidemic typhus, by von Prowazeck and da RochaLima. Both von Prowazeck and da Rocha-Lima got infected with the agent during their work and von Prowazeck died in 1915. Da Rocha-Lima named the agent after his colleague and friend. He later described another louse-transmitted infectious 


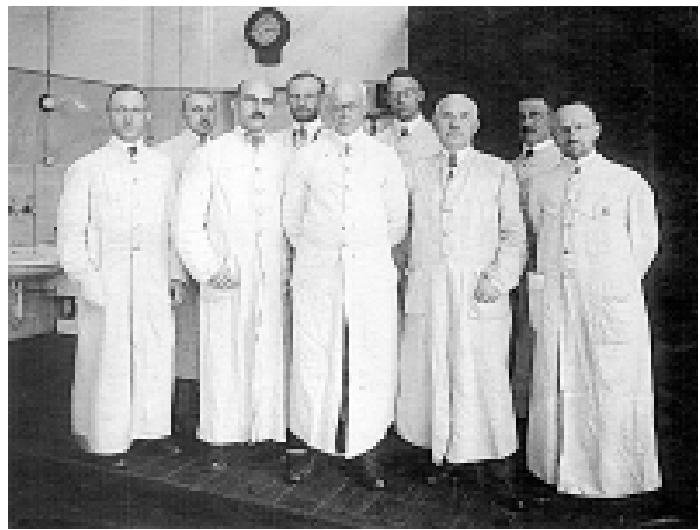

Fig. 1: members of the Institute for Maritime and Tropical Diseases in 1922. From left: 3rd, Henrique da Rocha-Lima; 5th, Bernhard Nocht; 7th, Gustav Giemsa; 8th, Eduard Reichenow

agent, Rochalimea (now Bartonella) quintana, the causing agent of trench fever. Von Prowazek also described for the first time the infectious origin of trachoma (Halberstaedter \& Prowazek 1909). As an animal model for the chemotherapy of malaria, the avian malaria was established and found suitable to test new derivatives of chinin such as plasmochin and atebrin. Using this model the protozoologist Eduard Reichenow and his coworkers described the extraerythrocytic development of plasmodial sporozoites as the missing link between the infective sporozoite and the infected erythrocyte (Reichenow \& Mudrow 1943).

The helminthologist Hans Vogel discovered in 1931 the developmental cycle of Opisthorchis felineus (Vogel 1934) and described later in experiments lasting from 1938 to 1950 , for the first time immunity against a trematode infection (Vogel \& Minning 1953). In the 50's, Vogel (1955) discovered Echinococcus multilocularis as a new species. More recent findings include the demonstration by Paul Racz and Klara Tenner-Racz together with Ashley Haase (Minneapolis) of a massive multiplication of HIV in the lymphnodes in the incubation period of Aids. Egbert Tannich was able in 1989 to separate Entamoeba histolytica and E. dispar (Tannich et al. 1989).

Nearly from its beginning the BNI had connections with the Instituto Oswaldo Cruz. Gustav Giemsa and Stanislaus von Prowazek stayed upon invitation by the Brazilian Government in 1908 in the Instituto Oswaldo Cruz (Fig. 3). In fact Giemsa was an author of the very first paper published by the Memórias do Instituto Oswaldo Cruz (Giemsa \& Godoy 1909). In September 1909, Nocht appointed Henrique da Rocha-Lima, who had been previously Head of the Department of Pathology

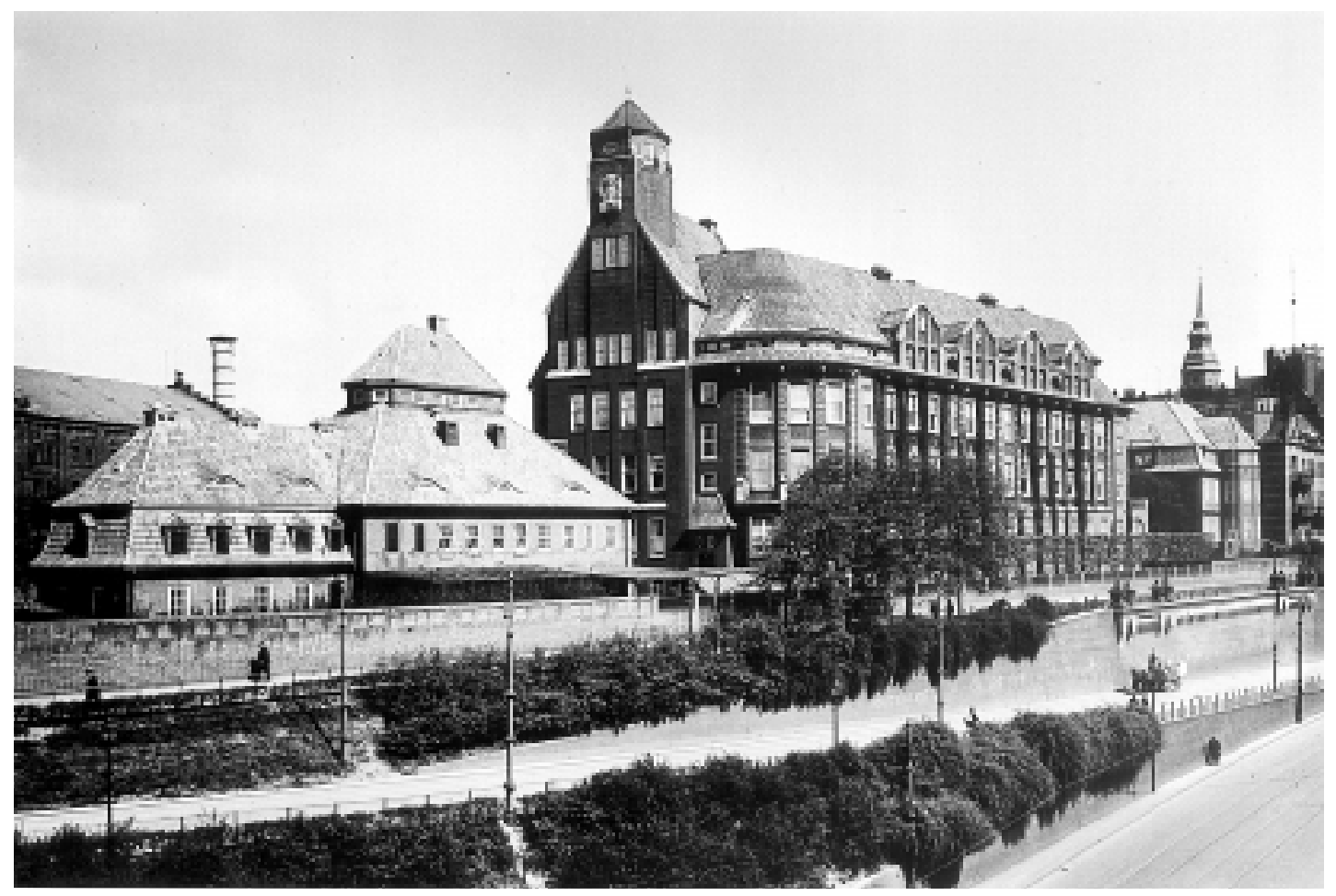

Fig. 2: the historical building of the Bernhard Nocht Institute at the front of the harbour in 1921 


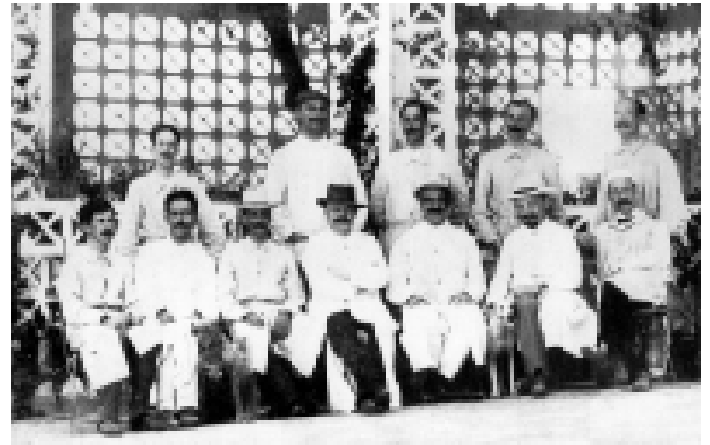

Fig. 3: Oswaldo Cruz between Gustav Giemsa and Stanislaus von Prowazek at the Instituto Manguinhos in 1908. With them are Carlos Chagas and Henrique da Rocha-Lima (2nd row from left).

at Instituto Oswaldo Cruz, as Head of a new Department of Pathology in his Institute. da RochaLima stayed until December 1927 in Hamburg. Nocht himself came in 1929 to visit the Instituto Oswaldo Cruz. In 1977, the Department of Electron Microscopy of the Instituto Oswaldo Cruz was established jointly with the BNI. Fig. 4 shows the head of BNI's Department of Protozoology, Prof. Heinz Mühlpfordt, demonstrating the use of the microscope to the President of Brazil Ernesto Geisel.

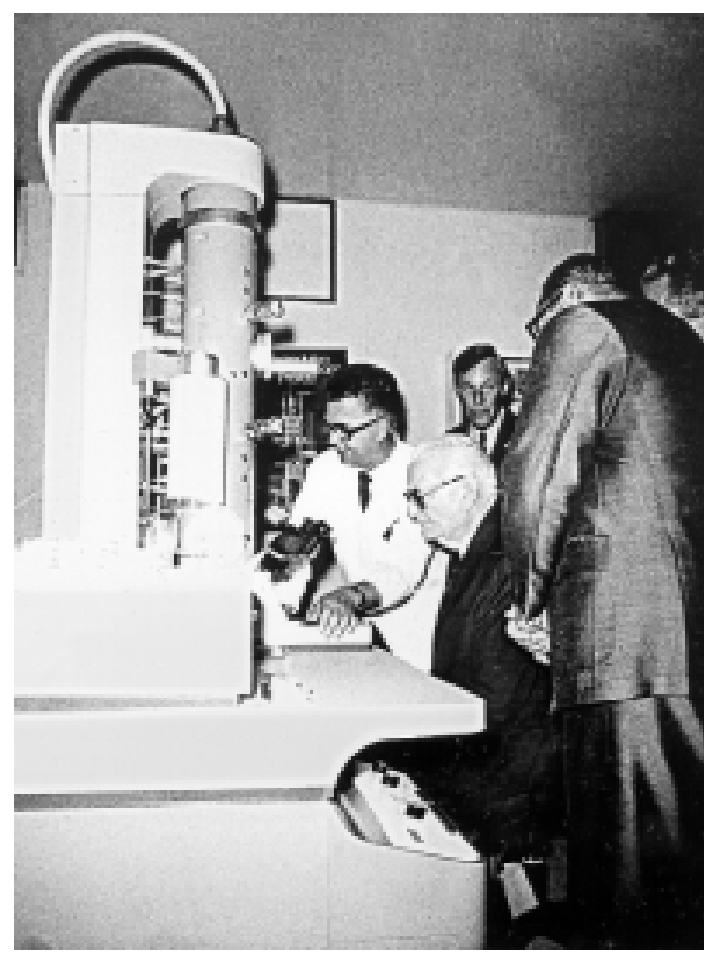

Fig. 4: installation of the electron microscope at the Instituto Oswaldo Cruz in 1977. Brazil's President Ernesto Geisel with Prof. Heinz Mühlpfordt of the Bernhard Nocht Institute at the microscope

\section{PRESENT}

One hundred years later, the BNI is still the Germany's largest research institute for tropical medicine. Research at the BNI is devoted to the characterization of host-pathogen-interactions in tropical infectious diseases. The research activities of the BNI concentrate on three areas: (1) cellular and molecular biology of infectious agents that cause tropical diseases; (2) the host response to such agents and its role in protection and pathology; (3) a disease oriented approach to pathogenesis and pathology. Accordingly BNI's work focuses on infectious diseases caused by parasites and tropical viruses. Main topics of work are pathogenicity factors of parasites and cell biology of parasites, the analysis of the host-parasite-relationship including immunological defense mechanisms, and definition of genes causing susceptibility to certain tropical infections. In all these ventures special emphasis is put on two issues: relevance for disease prevention and control, and use of tropical infections as models for general issues in medicine and biology.

The BNI is a government institution affiliated to the Federal Ministry of Health of the Federal Republic of Germany and the Ministry of Health of the State of Hamburg and is financed jointly by the Federal Government and the States of the Federal Republic of Germany. The BNI has many cooperations and contacts with developing countries, most of them with countries in Africa but also with countries in South America and Asia. The Institute maintains a Cooperative Research Center in Kumasi, Ghana, mainly for research on onchocerciasis and malaria. The cooperative center is established according to a state agreement between the Republic of Ghana and the State of Hamburg, to establish longstanding contacts to scientists of the host country. Its hallmark is that each research project is carried out jointly by scientists from Hamburg and from Kumasi. Projects on Lassa fever and amoebiasis are presently pursued in Guinea and Vietnam, respectively.

Besides research, the BNI has many educational and service activities in the area of tropical medicine. Three members of the BNI hold full professorships at the University of Hamburg and are engaged in teaching. A three-month's course on tropical medicine is held each year and is approved as an officially accredited diploma course by the American Society of Tropical Medicine and Hygiene. The BNI includes a Department of Clinical Medicine with 68 beds and an outpatient clinic where patients with tropical diseases are treated. The BNI performs specialized diagnostic tests for the detection of pathogens causing parasitic diseases. The Institute is equipped with the only true 
BSL4 laboratory in Germany for work with hemorrhagic fever viruses.

To fulfill its aims the BNI has a specific organizational structure. It is composed of three scientific sections (Parasitology, Medical Microbiology, Tropical Medicine) containing departments established for longer periods of time and temporary research groups. These research groups are installed for a limited period of time only and will be replaced by new groups according to scientific necessity. The Parasitology Section contains the Department of Molecular Parasitology and several research groups working on pathogenicity factors, biology of pathogens including biochemical pathways and mechanisms of adaptation and evasion. The Medical Microbiology Section contains the Departments of Immunology and Virology, research groups working on host-responses to filariae or to viruses, a Central Diagnostic Unit developing new diagnostic tools and the animal experimentation facilities. The Tropical Medicine Section contains the Departments of Molecular Medicine, Pathology, and Clinical Chemistry. The Department of Molecular Medicine runs the Kumasi Centre for Collaborative Research in Tropical Medicine in Kumasi, Ghana. The presence of a Clinical Department performing diagnosis and treatment of patients provides a distinctive advantage to the BNI. It is a valuable addition to the clinical research performed in the tropics because patients seen in Hamburg have usually primary infections with only one infecting agent, and intensive research applying high technology and follow-up studies for longer periods of time are possible in Hamburg.

\section{SPECIFIC RESEARCH PROGRAMS}

Amoebiasis research is a major research program in which scientists from several sections work together. This program covers a variety of aspects concerning the biology and pathogenicity of $E$. histolytica. In 1989, the group of Egbert Tannich had first described that pathogenic and non-pathogenic amoebae could be distinguished by molecular genetic methods (Tannich et al. 1989). In fact, the two species E. histolytica and E. dispar are as distant in evolution as mice and rats. Subsequently, the molecules serving as pathogenicity factors have been determined (Bruchhaus et al. 1996, Tannich 1998), among the cysteine proteins, the large 170 $\mathrm{kD}$ galactose specific surface lectin and the amoebapores, highly efficient and conserved poreforming proteins. Transfixion and stable expression of heterologous genes is now possible in $E$. histolytica and $E$. dispar allowing elucidating the role of various gene products in pathogenesis (Hamann et al. 1995). In vitro diagnostic tests have been developed to discriminate infection by pathogenic amoebae from infection by non-pathogenic amoebae. A possible candidate antigen for a vaccine has been identified (Lotter et al. 1997).

Filariasis research is the second major program of the BNI since the 60's. The main topic is onchocerciasis (river blindness) caused by the filaria, Onchocerca volvulus. Work on lymphatic filariasis especially on biochemical pathways possibly exploitable for the design of new antifilarial drugs, is also performed.

Adult $O$. volvulus worms developed from infective larval stages live in subcutaneous nodules from where they release microfilariae (MF) which migrate in the skin. The departments of Helminthology, Entomology, Molecular Genetics and Immunology cooperate in the definition of $O$. volvulus proteins and in the immunological effector mechanisms involved in anti-parasitic defense. The vectors transmitting infective larvae are studied and the differential susceptibility of exposed individuals which can be grouped into (i) patients with generalized disease, showing a high load of worms and MF accompanied by immunological tolerance against onchocercal antigens; (ii) patients with low MF load and immune reactivity leading to severe dermatitis; and (iii) putatively immune individuals that remain free of worms despite exposure to infective larvae. These forms of reactivity are associated with certain HLA class II antigens (Meyer et al. 1994). T cells from putatively immune individuals proliferate to onchocercal antigens and produce IL-5 and IFN- $\gamma$ in contrast to patients with generalized onchocerciasis. The defective response of the latter is due to production of the deactivating cytokines IL-10 and TGF- $\beta$. A T cell type resembling the $\mathrm{Th} 3$ or $\operatorname{Tr} 1$ regulatory $\mathrm{T}$ cells has been found in these patients. This $\mathrm{T}$ cell is specific for $O$. volvulus and its task may be a specific inhibition of $\mathrm{T}$ cell response by production of IL-10 and TGF at the same time scavenging IL-2 (Doetze et al. 2000).

The presence of endosymbiotic rickettsia-like bacteria of the genus Wolbachia in most filarial species has been known for more than 20 years. Achim Hoerauf et al. (1999) discovered in murine filariasis that these bacteria are susceptible to tetracycline antibiotics and that their depletion from the nematodes blocks worm development and abolishes fertility. They also demonstrated tetracycline to have no effect on the Wolbachia-free filaria Acanthocheilonema viteae, demonstrating that the antibiotic has no direct activity on nematodes. Then they conducted a tetracyclin treatment study on onchocerciasis patients in Ghana which showed that bacterial depletion can be achieved long-term and leads to a total and prolonged sterility of female 
worms (Hoerauf et al. 2000). The efficacy thus surpasses that of ivermectin and may render an antiWolbachia therapy as a new option for the treatment of filariasis. A combination therapy of doxycycline and ivermectin resulted in a significantly prolonged and enhanced amicrofilaridermia compared to sole ivermectin treatment (Hoerauf et al. unpublished). The finding that many of the pathogenetic sequelae of onchocerciasis are due to reactivity to Wolbachia antigen or LPS and not to $O$. volvulus itself (Brattig et al. 2000) has a bearing for the therapeutical interventions.

Aids research is also performed in a collaborative effort of several departments. The distribution of HIV is studied in the lymphoid tissue of patients and the antibody response to major neutralizing epitopes of HIV and the cellular immune response are characterized. Recent data from the Department of Pathology showed that the oral mucosal route is a most efficient route of infection due to rapid infection of oral mucosal-associated lymphoid tissue in the simian immunodeficiency virus system (Stahl-Hennig et al. 1999, Zhang et al. 1999a). The quantification of HIV in the lymphoid tissue and the enumeration of productively infected cells showed that the unenlarged lymph nodes of HIV1-infected, asymptomatic patients with high CD4 $\mathrm{T}$ cell counts are sites for virus replication and CD4 T cell proliferation (Tenner-Racz et al. 1998). This is found also in late stages of the disease and has important implications for therapeutical strategies (van Ende et al. 1999, Zhang et al. 1999b).

Malaria research is another program with institute-wide cooperations. Ongoing projects characterize the glutathione metabolism (Gilberger et al. 2000) and polyamine synthesis of Plasmodium falciparum. These studies demonstrate that the plasmodicidal effect of an inhibitor of glutathion synthesis does not depend on its specificity towards its target enzyme in the parasite, but on the changed physiological needs for the metabolite GSH in the $P$. falciparum-infected RBCs. Therefore the depletion of glutathione is proposed as a chemotherapeutic strategy for malaria, and gamma-glutamylcysteine synthetase is proposed as a potential drug target (Luersen et al. 2000). P. falciparum in contrast to other organisms presents a unique bifunctional ornithine decarboxylase plus Sadenosylmethionine decarboxylase, an organization which is possibly exploitable for the design of new antimalarial drugs (Muller et al. 2000).

Clinical studies on patients with severe malaria have supported the notion that the immune response of $\mathrm{T}$ cells may not be beneficial but rather contribute to pathology (Schlotmann et al. 2000). However, NO may have a beneficial rather than a deleterious role in falciparum malaria (Chiwakata et al. 2000). Ongoing work also characterizes the repertoire of sporozoite gene expression in the mosquito and the proteomics of rhoptry proteins. A molecular genetic approach is presently used to identify genes involved in susceptibility for or resistance to severe malaria as well as to other tropical infections such as onchocerciasis. This approach involves the scanning of the genome in families with defined manifestations of infectious diseases.

Besides these major areas of research, a variety of other agents and issues is investigated. These include the regulation of heat-shock protein expression in Leishmania. Novel heat shock proteins are identified, their role in infectivity is determined by genetic manipulation. Candidate target molecules are identified for chemotherapy of filariasis and malaria. Key enzymes involved in metabolism of glutathion and polyamines in filariae are characterized and cloned. Parasite-specific peculiarities of such molecules are exploited as an approach for rational drug design. Oligogenic linkage and segregation analysis is performed to identify loci influencing the intensity of infection with Schistosoma mansoni and $O$. volvulus. The epidemiology of filariasis and the occurence in the vectors is studied. The immune response to Trypanosoma cruzi in patients with Chagas disease is studied. The role of different $T$ cell subpopulations and the effect of infections on the behaviour of antigen-presenting cells by $T$. cruzi are studied. The immune response to an effector mechanisms against $T$. cruzi and the rodent filaria Litomosoides sigmodontis are analyzed in mice (Al-Qaoud et al. 2000). The immune mechanisms and possible targets for vaccination and therapy are studied in such model systems. Novel strategies of vaccination such as peptideloaded heat shock proteins (Breloer et al. 1999) may be promising in this respect.

The BNI is the only federal institute in the Federal Republic of Germany equipped with a maximum containment laboratory (BSL4) for work with hemorrhagic fever viruses. The Institute performs diagnostic tests for tropical virus infections and pursues research on epidemiology, virology and immunology of Lassavirus, Denguevirus and Hantavirus infections (ter Meulen et al. 2000). The recent imported cases of Lassa fever from West Africa have demonstrated the essential role of the BNI for the diagnosis and handling of such cases in Germany.

\section{OUTLOOK}

In the century of the existence of BNI, parts of tropical medicine have changed dramatically, modern techniques in molecular biology, immunology and genetics have changed the scientific look at a 
parasite or a disease. In other parts, however, tropical medicine faces the same problems as decades ago. More and novel ones are to come. Overpopulation, migration, globalization, megacities, mass travel and rapid spread of infectious agents are paradigms of future problems. At the beginning of the second century of the existence of Instituto Oswaldo Cruz and Bernhard Nocht Institute their research on infectious diseases is needed as urgently as ever. Today our generation has a number of weapons against infectious agents at hand due to the research financed by previous generations. We owe it to the next generations not to cease in the permanent effort to combat these diseases.

\section{REFERENCES}

Al-Qaoud KM, Pearlman E, Klukowski J, Hartung T, Fleischer B, Hoerauf A 2000. Interleukin-5 is required for neutrophil-mediated worm elimination in murine filariasis. Int Immunol 12: 899-908.

Brattig NW, Rathjens U, Ernst M, Geisinger F, Renz A, Tischendorf FW 2000. Lipopolysaccharide like molecules derived from Wolbachia endobacteria of the filaria Onchocerca volvulus are candidate mediators in the sequence of inflammatory and antiinflammatory responses of human monocytes. Microb Infect 2 , in press.

Breloer M, Fleischer B, von Bonin A 1999. In vivo and in vitro activation of $\mathrm{T}$ cells following administration of antigen-negative heat shock proteins. $J$ Immunol 162: 3141-3147.

Bruchhaus I, Jacobs T, Leippe M, Tannich E 1996. Entamoeba histolytica and Entamoeba dispar: differences in numbers and expression of cysteine proteinase genes. Mol Microbiol 22: 255-263.

Chiwakata CB, Hemmer CJ, Dietrich M 2000. High levels of inducible nitric oxide synthase mRNA are associated with increased monocyte counts in blood and have a beneficial role in Plasmodium falciparum malaria. Infect Immun 68: 394-399.

Doetze A, Satoguina J, Burchard G, Rau T, Fleischer B, Hoerauf A 2000. Antigen-specific cellular hyporesponsiveness in generalized onchocerciasis is mediated by Th3/Tr1-type cytokines IL-10 and TGF- $\beta$ but not by a Th1 to Th2 shift. Int Immunol 12: 623-630.

Giemsa G, Godoy A 1909. Sobre a ultrafiltração. Pesquisas tendentes a obter a concentração do soro antidifterico. Ueber Filtration und Versuche, mit Hilfe derselben Diphterieserum zu konzentrieren. Mem Inst Oswaldo Cruz 1: 3-11.

Gilberger T, Schirmer RH, Walter RD, Muller S 2000. Deletion of the parasite-specific insertions and mutation of the catalytic triad in glutathione reductase from chloroquine-sensitive Plasmodium falciparum 3D7. Mol Biochem Parasitol 107: 169-179.

Halberstaedter L, von Prowazek S 1909. Ueber Chlamydozoenbefunde bei Blennorrhoea neonatorum non gonorrhoica. Berl klin Wochenschr 46: 1839-1840.
Hamann L, Nickel R, Tannich E 1995. Transfixion and continuous expression of heterologous genes in the protozoan parasite Entamoeba histolytica. Proc Natl Acad Sci USA 92: 8975-8979.

Hoerauf A, Nissen-Pähle K, Schmetz C, K H-D, Blaxter ML, Büttner DW, Gallin MY, Al-Qaoud KM, Lucius R, Fleischer B 1999. Tetracycline therapy targets intracellular bacteria in the filarial nematode Litomosoides sigmodontis and results in filarial infertility. J Clin Invest 103: 11-18.

Hoerauf A, Volkmann L, Hamelmann C, Adjei O, Autenrieth IB, Fleischer B, Büttner DW 2000. Endosymbiotic bacteria in worms as targets for a novel chemotherapy in filariasis. Lancet 355: 1242-1243.

Lotter H, Zhang T, Seydel KB, Stanley SL Jr, Tannich E 1997. Identification of an epitope on the Entamoeba histolytica $170-\mathrm{kD}$ lectin conferring antibodymediated protection against invasive amebiasis. $J$ Exp Med 185: 1793-1801.

Luersen K, Walter RD, Muller S 2000. Plasmodium falciparum-infected red blood cells depend on a functional glutathione de novo synthesis attributable to an enhanced loss of glutathione. Biochem J 346: 545552.

Meyer CG, Gallin M, Erttmann KD, Brattig N, Schnittger L, Gelhaus A, Tannich E, Begovich AB, Erlich HA, Horstmann RD 1994. HLA-D alleles associated with generalized disease, localized disease, and putative immunity in Onchocerca volvulus infection. Proc Natl Acad Sci USA 91: 7515-7519.

Muller S, Da'dara A, Luersen K, Wrenger C, Das Gupta R, Madhubala R, Walter RD 2000. In the human malaria parasite Plasmodium falciparum, polyamines are synthesized by a bifunctional ornithine decarboxylase, S-adenosylmethionine decarboxylase. J Biol Chem 275: 8097-8102.

Reichenow E, Mudrow L 1943. Der Entwicklungsgang von Plasmodium praecox im Vogelkörper. Dtsch Tropenmed Z 47: 289-299.

Schlotmann T, Waase I, Julch C, Klauenberg U, MullerMyhsok B, Dietrich M, Fleischer B, Broker BM 2000. CD4 alphabeta T lymphocytes express high levels of the T lymphocyte antigen CTLA-4 (CD152) in acute malaria. $J$ Infect Dis 182: 367-370.

Stahl-Hennig C, Steinman RM, Tenner-Racz K, Pope M, Stolte N, Matz-Rensing K, Grobschupff G, Raschdorff B, Hunsmann G, Racz P 1999. Rapid infection of oral mucosal-associated lymphoid tissue with simian immunodeficiency virus. Science 285: 1261-1265.

Tannich E, Horstmann RD, Knobloch J, Arnold HH 1989. Genomic DNA differences between pathogenic and nonpathogenic Entamoeba histolytica. Proc Natl Acad Sci USA 86: 5118-5122.

Tannich E 1998. Amoebic disease. Entamoeba histolytica and E. dispar: comparison of molecules considered important for host tissue destruction. Trans $R$ Soc Trop Med Hyg 92: 593-596.

Tenner-Racz K, Stellbrink HJ, van Lunzen J, Schneider C, Jacobs JP, Raschdorff B, Grosschupff G, Steinman RM, Racz P 1998. The unenlarged lymph nodes of HIV-1-infected, asymptomatic patients with 
high CD4 T cell counts are sites for virus replication and CD4 $\mathrm{T}$ cell proliferation. The impact of highly active antiretroviral therapy. J Exp Med 187: 949-959.

ter Meulen J, Badusche M, Kuhnt K, Doetze A, Satoguina J, Marti T, Loeliger C, Koulemou K, Koivogui L, Schmitz H, Fleischer B, Hoerauf A 2000. Characterization of human CD4+ T-cell clones recognizing conserved and variable epitopes of the Lassa virus nucleoprotein. J Virol 74: 2186-2192.

van der Ende ME, Schutten M, Raschdorff B, Grossschupff G, Racz P, Osterhaus AD, Tenner-Racz K 1999. CD4 T cells remain the major source of HIV1 during end stage disease. AIDS 13: 1015-1019.

Vogel H 1934. Der Entwicklungszyklus von Opistorchis felineus. Far East Assoc Trop Med (Nanking) 1: 619-624.

Vogel H 1955. Über den Entwicklungszyklus und die Artzugehörigkeit des europäischen Alveolarechino- coccus. Dtsch Med Wschr 80: 931-932.

Vogel H, Minning W 1953. Über die erworbene Resistenz von Macacus rhesus gegenüber Schistosoma mansoni. T. Z Tropenmed Parasit 4: 418-505.

Zhang L, Ramratnam B, Tenner-Racz K, He Y, Vesanen M, Lewin S, Talal A, Racz P, Perelson AS, Korber BT, Markowitz M, Ho DD 1999b. Quantifying residual HIV-1 replication in patients receiving combination antiretroviral therapy. $N$ Engl J Med 340: 1605-1613.

Zhang Z, Schuler T, Zupancic M, Wietgrefe S, Staskus KA, Reimann KA, Reinhart TA, Rogan M, Cavert W, Miller CJ, Veazey RS, Notermans D, Little S, Danner SA, Richman DD, Havlir D, Wong J, Jordan HL, Schacker TW, Racz P, Tenner-Racz K, Letvin NL, Wolinsky S, Haase AT 1999a. Sexual transmission and propagation of SIV and HIV in resting and activated CD4+ T cells. Science 286: 1353-1357. 